\title{
International Prostate Symptom Score
}

National Cancer Institute

\section{Source}

National Cancer Institute. International Prostate Symptom Score. NCI Thesaurus. Code C113446.

A screening tool used to screen for, diagnose, track, and manage the symptoms of benign prostatic hyperplasia. 